ÉGYPTE

monde arabe

\section{Égypte/Monde arabe}

5-6| 2009

Pratiques du Patrimoine en Égypte et au Soudan

\title{
Nationalisme, impérialisme et pratiques patrimoniales : le cas de la Mahdiyya dans le Soudan post-mahdiste
}

Nationalism, Imperialism and practices of heritage: the case of the Mahdiyya in the post-Mahdist Sudan

Iris Seri-Hersch

\section{OpenEdition}

Journals

Édition électronique

URL : https://journals.openedition.org/ema/2906

DOI : 10.4000/ema.2906

ISSN : 2090-7273

Éditeur

CEDEJ - Centre d'études et de documentation économiques juridiques et sociales

Édition imprimée

Date de publication : 22 décembre 2009

Pagination : 329-354

ISBN : 2-905838-43-4

ISSN : $1110-5097$

\section{Référence électronique}

Iris Seri-Hersch, «Nationalisme, impérialisme et pratiques patrimoniales : le cas de la Mahdiyya dans le Soudan post-mahdiste », Égypte/Monde arabe [En ligne], 5-6 | 2009, mis en ligne le 31 décembre 2010, consulté le 07 juillet 2022. URL : http://journals.openedition.org/ema/2906 ; DOI : https:// doi.org/10.4000/ema.2906 


\section{RÉSUMÉ / ABSTRACT}

\section{NATIONALISME, IMPÉRIALISME ET PRATIQUES PATRIMONIALES : LE CAS DE LA MAHDIYYA DANS LE SOUDAN POST-MAHDISTE}

Cet article examine les pratiques patrimoniales développées autour de la Mahdiyya soudanaise (1881-1898) durant le condominium anglo-égyptien (1899-1956). Tout en tenant compte de l'évolution sémantique des concepts de patrimoine et de turâth, il vise à montrer que cette période controversée de l'histoire soudanaise fut l'enjeu de processus de patrimonialisation, de dépatrimonialisation et de contre-patrimonialisation déclenchés par des acteurs aux intérêts politiques et idéologiques très divergents : les néo-mahdistes qui avaient pour objectif I'accession du Soudan à une indépendance totale ; les unionistes qui préconisaient I'union politique du Soudan avec l'Égypte; et les administrateurs britanniques pour qui l'établissement d'un système colonial effectif impliquait l'anéantissement matériel et symbolique du régime mahdiste.

\section{NATIONALISM, IMPERIALISM AND PRACTICES OF HERITAGE: THE CASE OF THE MAHDIYYA IN THE POST-MAHDIST SUDAN}

This article deals with heritage practices developed around the Mahdiyya in the Sudan during the Anglo-Egyptian Condominium (1899-1956). Underlining the semantic evolution of concepts such as heritage and turâth, I show that the Mahdiyya, a controversial period in Sudanese history (1881-1898), was later subjected to contradictory and competing heritagemaking processes. NeoMahdist leaders made it into a Sudanese national heritage in order to serve their aim of a fully independent Sudan. Their Unionist rivals, who advocated political unity between Egypt and the Sudan, sought to hinder such nationalization of the Mahdiyya. As for British administrators, they actively promoted the material and symbolic annihilation of the Mahdist regime. They initiated counter-heritage-making processes centred on their martyred hero General Gordon with a view to legitimize and consolidate British control in the Sudan. 



\title{
NATIONALISME, IMPÉRIALISME ET PRATIQUES PATRIMONIALES : LE GAS DE LA MAHDIYYA DANS LE SOUDAN POST-MAHDISTE
}

\begin{abstract}
A près la chute de l'État mahdiste soudanais, matérialisée par la bataille de Kararî (Septembre 1898) et la mort du Khalîfa 'Abdullâhi à Umm Dibaykrât (Novembre 1899), le commandant de l'armée anglo-égyptienne conquérante - Herbert Kitchener - constata triomphalement que la Mahdiyya n'était " plus qu'un souvenir ». ${ }^{1}$

Face à I'anéantissement physique et institutionnel du régime mahdiste, Kitchener pouvait difficilement imaginer que la mémoire de la Mahdiyya, entretenue et remodelée par certains secteurs de la société soudanaise, remplirait une fonction politique et idéologique majeure tout au long du Condominium anglo-égyptien (1898-1956). En tant qu'enjeu de différents processus de patrimonialisation, de " dé-patrimonialisation » et de " contrepatrimonialisation », cette période controversée de l'histoire soudanaise joua un rôle crucial dans le conflit politique et identitaire qui, durant la première moitié du XXe siècle, allait opposer deux grands ensembles d'acteurs : d'un
\end{abstract}

\footnotetext{
Note de l'auteur: J'adresse mes vifs remerciements à Ghislaine Alleaume (IREMAM), Micha Hersch et Dov Pine pour avoir lu et commenté la version initiale de cet article, ainsi qu'à Jane Hogan (Sudan Archive, Durham) pour sa disponibilité et son soutien. 1. 'Abd al-Rahmân al-Khânajî, " al-judhûr al-fikriyya li-thaurat 1924 » in Mahâsin 'Abd al-Qâdir Hâjj al-Sâfî, al-haraka al-wataniyya fî-I-Sûdân, thaurat 1924, Khartoum, matbacat jâmicat al-Khartûm, 1992, p. 85. La Mahdiyya désigne le mouvement mahdiste qui réussit à établir une structure étatique indépendante au Soudan entre 1881 et 1898. Le terme peut également se référer à la période 1881-1898 dans le contexte de l'histoire soudanaise.
} 
côté, les Ansâr ${ }^{2}$ (ou « néo-Mahdistes ») cherchaient à atteindre l'objectif d'un Soudan indépendant à travers une collaboration pragmatique avec le régime colonial britannique ; de l'autre, les « Unionistes», soutenus par une confrérie soufie (tarîqa) historiquement opposée aux Mahdistes (Khatmiyya) et par les nationalistes égyptiens, défendaient l'idéologie de l'unité de la vallée du Nil préconisant l'union politique de l'Égypte et du Soudan. Loin d'être rigides, ces alliances prenaient fréquemment I'air de mariages de circonstance qui évoluaient au gré de configurations stratégiques locales, régionales et internationales. $^{3}$

Depuis une vingtaine d'années, les questions relatives au patrimoine font l'objet d'un débat animé parmi les chercheurs en sciences humaines et sociales. Plus qu'une simple mode, cet intérêt scientifique découle en partie d'une remarquable évolution sémantique des concepts eux-mêmes. Quelques notions sont particulièrement pertinentes pour notre étude : le patrimoine, les processus dérivés de patrimonialisation, dé-patrimonialisation et contrepatrimonialisation (élaborés dans un contexte européen), ainsi que le turâth (élaboré dans un contexte arabo-musulman).

À la fin du XXe siècle, plusieurs chercheurs diagnostiquent une «triple extension typologique, chronologique et géographique des biens patrimoniaux, accompagnée d'une croissance exponentielle de leur public ». ${ }^{4}$ L'expansion, la diffusion et la dilution contemporaines du concept de patrimoine se sont ainsi opérées à différents niveaux. Le premier est spatial, impliquant un changement d'échelle majeur. Le champ d'application de la notion a évolué d'un espace privé/familial à un espace public/collectif, qu'il soit régional, national,

2. Ainsi les partisans du Mahdî se nommaient-ils, en référence aux premiers disciples médinois du Prophète Muhammad. Cette appellation continua à être employée au $\mathrm{XX}$ e siècle pour désigner les adhérents au mouvement religieux néo-mahdiste dirigé par les descendants du Mahdî.

3. C'est avant tout l'attitude de la Grande Bretagne qui évolua fréquemment. Elle eut par exemple tendance, au cours des premières décennies du Condominium, à soutenir la Khatmiyya afin de contrer une éventuelle résurgence mahdiste dont elle craignait l'impact déstabilisateur. Sa conduite à l'égard des néo-Mahdistes fut continuellement ambivalente, oscillant entre une politique répressive et des marques de soutien et de reconnaissance lorsque ses intérêts l'exigeaient.

4. Françoise Choay, L'allégorie du patrimoine, Paris, Seuil, 1992, p. 12 ; Dominique Poulot, "Le sens du patrimoine, hier et aujourd'hui », Annales. Histoire, Sciences Sociales, Vol. 6, 1993, p. 1607. 
voire mondial. Désignant fondamentalement des biens de famille hérités ${ }^{5}$, le patrimoine s'est en effet élargi à des biens collectifs transmis au groupe par les ancêtres. En France, l'idée d'un patrimoine culturel national se développe dans le sillage de la Révolution. ${ }^{6}$ La création de multiples institutions internationales après la seconde guerre mondiale affecte directement le domaine du patrimoine: I'Unesco adopte en 1972 la Convention pour la protection du Patrimoine mondial culturel et naturel. Doté d'une reconnaissance officielle, le patrimoine mondial est désormais considéré comme un bien en péril qu'il $\mathrm{s}^{\prime}$ agit à tout prix de sauvegarder. ${ }^{7}$

La seconde transformation importante est d'ordre typologique. Constitué d'abord par des chefs-d'œuvre d'architecture monumentale et des objets somptuaires, le patrimoine s'est étendu à la "petite » architecture et aux objets utilitaires, investissant les champs du banal et de l'ordinaire. Il s'est ensuite détaché du monde matériel pour englober des biens immatériels et invisibles. Ainsi, dans le cadre national, le patrimoine a pu non seulement être identifié aux vestiges matériels du passé national, mais également à la " richesse morale de la nation toute entière ${ }^{8}{ }^{8}$

L'éclatement du concept en une myriade d'acceptions et d'usages a inquiété plus d'un chercheur, l'un constatant que le patrimoine est devenu " la totalité du passé », un second avertissant des débordements possibles d'une "prolifération patrimoniale », alors qu'un troisième propose malicieusement le néologisme "patrimomania » tout en se demandant si le patrimoine n'est pas une "notion fourre-tout » à l'ère post-moderne. ${ }^{9}$ Malgré le flou sémantique qui l'enveloppe et le péril épistémologique qui le guette, le concept de patrimoine conserve deux aspects fondamentaux pour notre réflexion:

5. Le patrimoine est issu de la notion juridique romaine de patrimonium, qui est composée de deux racines : le "père » et le "monument». Le patrimoine est en ce sens un « signe monitoire adressé par le père à ses descendants pour que ceux-ci le gardent en mémoire, dans leur esprit (mens). »Cf. Nicolas Martin-Granel, « Malaise dans le patrimoine ", Cahiers d'Etudes Africaines, Vol. 39, 155, 1999, p. 496.

6. La Révolution française est tantôt assimilée au phénomène traumatisant du vandalisme, tantôt aux fondements éthiques et politiques de la conscience patrimoniale contemporaine. Cf. Poulot, « Le sens du patrimoine », p. 1601.

7. Christian Bachelier, «La notion de patrimoine ", Bulletin de l'Institut d'Histoire du Temps Présent, Vol. 43, 1991, p. 20.

8. André Chastel, "La notion de patrimoine " in Pierre Nora, (éd.), Les lieux de mémoire. II. La Nation**, Paris, Gallimard, 1986, p. 411.

9. Cf. respectivement André Fermigier cité par Bachelier, "La notion de patrimoine », 21 ; Poulot, "Le sens du patrimoine », p. 1608 ; Martin-Granel, "Malaise dans le patrimoine », p. 490, p. 506. 
il s'agit d'abord d'un bien collectif transmis (subi) ou approprié (activement élaboré). Ensuite, les champs de transmission et d'appropriation de ce bien ont historiquement évolué de la sphère familiale à la sphère nationale. Ces deux paramètres sont centraux dans les processus de patrimonialisation que nous mettrons en évidence dans notre analyse. Ces processus se réfèrent à la transformation d'objets matériels et immatériels en propriété collective d'un groupe. Le fils n'est pas (plus) le récepteur passif de l'héritage transmis par son père, mais bien plutôt un acteur qui s'approprie cet héritage tout en le destinant à un collectif d'héritiers plus large. En tant que biens collectifs activement élaborés et appropriés, les patrimoines sont I'enjeu de choix et de conflits exacerbés. Ils deviennent des fragments de la construction sociale de I'identité. Ils peuvent alors représenter une mémoire commune que certains tentent d'inventer, de préserver ou de prolonger, alors que d'autres visent à la faire disparaître. ${ }^{10}$ La patrimonialisation se heurte ainsi à des dynamiques opposées de dé-patrimonialisation ou de contre-patrimonialisation. Ces dernières visent à désapproprier le groupe du bien qu'on lui a ou qu'il s'est lui-même approprié. Alors que la dé-patrimonialisation emploie des outils de destruction (physique, spirituelle) et de déconstruction (politique, intellectuelle), la contre-patrimonialisation élabore des contre-modèles pourvus d'une puissante fonction délégitimatrice.

Le parcours sémantique du concept de turâth peut-il être mis en parallèle avec celui du patrimoine ? L'évolution des usages de ces notions à travers le temps comporte certaines similitudes, mais également quelques différences majeures. À l'instar du patrimoine, le terme arabe "turâth » se référait initialement à l'héritage familial ${ }^{11}$ et a subséquemment enduré une dilatation sémantique notable. À partir de la seconde moitié du XIXe siècle, le turâth désigne la tradition islamique qui perpétue les systèmes de valeur de I'Islam à travers la langue arabe. Le mouvement de la renaissance arabe (nahda) produisit un discours qui idéologisa le turâth en en faisant à la fois un mécanisme de soutien à la réforme (retour aux sources de la religion) et un mécanisme de défense contre la menace politique, technique, militaire et intellectuelle occidentale. ${ }^{2}$ Plus qu'une tradition à préserver et à transmettre, le turâth est

10. Jacques Le Goff, "Introduction des Entretiens du Patrimoine » in Jacques Le Goff, (éd.), Patrimoine et passions identitaires. Actes des Entretiens du Patrimoine, Paris, Fayard, 1998, p. 13.

11. Le tâ de turâth était originellement un waw, ce qui l'associait au lexique de l'héritage dérivé de la racine wa-ra-tha. Cf. Nelly Lahoud, "Tradition (turâth) in contemporary Arabic political discourse », Critique: Critical Middle Eastern Studies, Vol. 13, 3, 2004, p. 323, note 35.

12. Muhammad 'Abîd al-Jâbirî, al-turâth wa-l-hadâtha, Beyrouth, markaz dirâsât alwahda al-carabiyya, 1991, cité par ibid., p. 323. 
aujourd'hui associé à un réservoir de données culturelles, intellectuelles, religieuses et artistiques à l'aide desquelles les intellectuels du monde arabomusulman façonnent et légitiment des identités politiques actuelles. L'une des dissemblances cruciales entre les concepts de patrimoine et de turâth réside dans le fait que ce dernier n'incorpora que récemment des objets matériels et construits dans son acception, dépossédant ainsi les waqf et les athâr de leurs protégés. ${ }^{13}$ Le patrimoine fut sujet à une évolution opposée, puisqu'il concerna d'abord des biens matériels avant d'inclure des biens immatériels.

Tentons a présent de tester ces concepts dans un cadre historique soudanais particulier, en nous posant la question suivante : comment la Mahdiyya fut-elle patrimonialisée, dé-patrimonialisée et contre-patrimonialisée pendant et après le Condominium anglo-égyptien, par quels acteurs et à quelles fins ? Nous réserverons une analyse particulière à la figure de proue du mouvement néo-mahdiste incarnée par Sayyid cAbd al-Rahmân al-Mahdî (1885-1959, ciaprès S.A.R), fils posthume du Mahdî. Nous ne négligerons cependant pas les postures patrimoniales de ses contemporains - Soudanais ou administrateurs britanniques - et d'historiens plus tardifs.

\section{LA MAHDIYYA ENTRE PATRIMONIALISATION NATIONALE ET APPRO- PRIATION FAMILIALE}

Parvenu à maturité au cours des premières années du Condominium angloégyptien, S.A.R. se fixa pour objectif de restaurer le mouvement mahdiste détruit par la "reconquête ${ }^{14}$ anglo-égyptienne du Soudan. N'étant pas un homme révolutionnaire, il opta pour une prudente coopération avec l'administration britannique qu'il parvint fréquemment à manipuler afin de promouvoir ses propres intérêts. ${ }^{15}$ Son ultime ambition était de régner sur un Soudan indépendant de toute tutelle étrangère. Ceci impliquait d'habiller le mouvement néo-mahdiste d'un vêtement nationaliste particulariste symbolisé par le slogan

13. CEDEJ, « Fabriques et pratiques du patrimoine, appel à contributions », [en ligne] http://www.cedej-eg.org/article.121(9 novembre 2009).

14. L'invasion du Soudan par les forces anglo-égyptiennes entre 1896 et 1899 fut présentée par les Britanniques comme une "reconquête », en référence au régime turco-égyptien antérieur à la Mahdiyya.

15. Pour une étude détaillée et récente du néo-Mahdisme dans le Soudan angloégyptien, cf. Hassan Ahmed Ibrahim, Sayyid 'Abd al-Rahmân al-Mahdî, A Study of Neo-mahdism in the Sudan, 1899-1956, Leiden, Brill, 2004. Cet ouvrage voit dans le charisme et les capacités de S.A.R. à manipuler ses opposants politiques (britanniques, soudanais, égyptiens), les facteurs-clés de l'émergence du néo-Mahdisme en tant que mouvement politico-religieux de masse au XXe siècle. 
"Le Soudan aux Soudanais $» .{ }^{16}$ L'un des aspects importants de la stratégie de S.A.R. consistait à transformer la Mahdiyya en patrimoine national du peuple soudanais. En effet, cette patrimonialisation lui permettait de légitimer ses revendications politiques : puisque la révolution mahdiste avait conduit à un État soudanais indépendant à la fin du XIXe siècle, il lui incombait, au nom de tous les Soudanais, de restituer cette indépendance au $X X^{\mathrm{e}}$ siècle. S.A.R. proposa donc une réinterprétation nationaliste de la Mahdiyya, qu'il compléta par des actes publics investis d'une forte charge symbolique.

Selon S.A.R., la prédication de son père le Mahdî établit le concept du sacrifice (tadhiyya) individuel et collectif comme un fondement de la Mahdiyya. L'esprit de sacrifice partagé par les Ansâr fut à l'origine d'un mode de vie ascétique et d'une attitude héroïque qui n'attribuait à la lutte pour l'expansion du Mahdisme que deux issues possibles: la victoire (nasr) ou le martyre (chahâda). ${ }^{17}$ Plus encore, cet esprit de sacrifice transforma des tribus éparpillées en une communauté (umma) croyante et militante, prête à affronter les ennemis régionaux et les puissances européennes rivales. ${ }^{18}$ Cette communauté était non seulement unie par l'esprit du sacrifice, mais également par un sentiment de fraternité (ikhâ) issu d'une piété et d'un amour de l'imam partagés. S.A.R. affirme que le Soudan tout entier s'apprêta à rejoindre la Mahdiyya en réponse à l'appel du Mahdî, soulignant ainsi la portée territoriale du mouvement. De plus, il emploie le verbe « libérer» (harrara) pour décrire la prise de Khartoum par les Mahdistes, épousant une terminologie résolument nationaliste. ${ }^{19}$ La Mahdiyya aurait donc généré une communauté unie sur un territoire défini, partageant les mêmes valeurs morales et religieuses, et poursuivant un objectif militant commun. La nation soudanaise ainsi décrite par S.A.R. se voit attribuer une date et un lieu de naissance extrêmement précis : au mois de

16. L'expérience coloniale particulière du Soudan, marquée par deux puissances dominantes, la Grande Bretagne et l'Égypte, donna lieu à deux modes d'expression nationaliste distincts dès la fin de la première guerre mondiale : l'idéologie de l'unité de la vallée du Nil et celle du Soudan aux Soudanais. Cf. Muddathir 'Abd al-Rahîm, "Arabism, Africanism and Self-Identification in the Sudan», Journal of Modern African Studies, Vol. 8, 2, 1970, p. 242 ; John O. Voll, "Mahdis, Walis and New Men in the Sudan » in Nikki R. Keddie, éd., Scholars, Saints and Sufis. Muslim Religious Institutions in the Middle East since 1500, Berkeley, University of California Press, 1972, p. 372.

17. 'Abd al-Rahmân al-Mahdî, Mudhakkarât al-Imâm ' ${ }^{c}$ Abd al-Rahmân al-Mahdî, Le Caire, markaz al-dirâsât al-sûdâniyya, 1996, p. 26.

18. Ibid., p. 29.

19. Ibid., p. 27. Le fait que Khartoum ait été fondée dans les années 1820 par les conquérants turco-égyptiens du Soudan - ceux-là même contre lesquels le Mahdî lutta - accentue l'ironie créée par l'usage du terme « libérer». 
Shacbân 1298 / juin 1881 sur l'île d'Aba (manifestation du Mahdî). La création de la nation soudanaise ne serait autre que l'œuvre du Mahdî.

Au cours de son long parcours politique, S.A.R. adopta un comportement public qui visait à fabriquer un patrimoine national tantôt par l'adoption d'attitudes politico-idéologiques propres aux Mahdistes, tantôt par la transformation sémantique et symbolique d'objets matériels hérités de la Mahdiyya. Exposons un exemple concret relatif à chaque cas. Bien qu'ils l'aient surveillé avec méfiance depuis l'établissement du Condominium, les Britanniques décidèrent de louer les services de S.A.R. durant la première guerre mondiale. Engagé aux côtés de l'Allemagne, le Sultan ottoman avait appelé tous les Musulmans au djihad contre les puissances alliées, posant ainsi une menace aux puissance impériales régnant sur des populations musulmanes. Le gouverneur général du Soudan, Sir Reginal Wingate, décida d'utiliser l'influence de S.A.R. pour obtenir le soutien des habitants du pays. Lors d'une tournée dans la Gezira en décembre 1915, le fils du Mahdî exhorta non seulement les Ansâr, mais tous les Soudanais, à combattre les «Turcs infidèles ". ${ }^{20}$ Cet appel faisait curieusement écho au djihâd déclaré par le Mahdî entre 1881 et 1885, réactivant une tradition d'hostilité à l'encontre des «Turcs».

La fin du conflit mondial offre un très bel exemple de la façon dont S.A.R. parvenait à mettre en scène I'héritage matériel mahdiste tout en lui attribuant un sens qui corresponde à ses projets politiques. En avril 1919, S.A.R. fut inclus dans une délégation de leaders soudanais envoyés à Londres afin d'exprimer leur allégeance à la Grande Bretagne et féliciter le Roi George V pour la victoire alliée. Bien qu'il n'ait pas été le chef officiel de la délégation, S.A.R. offrit au Roi une épée qu'il affirma être celle de son père. ${ }^{21}$ Produit un mois après la révolte nationale égyptienne (mars 1919), ce geste symbolisait l'appui des Ansâr à la Grande Bretagne dans sa lutte contre le nationalisme égyp-

20. Peter M. Holt, "Sudanese Nationalism and Self-Determination, part I », The Middle East Journal, Vol. 10, 3, 1956, p. 242; Gabriel R. Warburg, "From Revolution to Conservatism: Some Aspects of Mahdist Ideology and Politics in the Sudan », Der Islam, Vol. 70, 1, 1993, p. 99. Le terme «Turcs » était employé par les habitants du Soudan au XIXe siècle pour désigner les occupants turco-égyptiens. Cependant, son acception s'élargit rapidement à tous les membres des élites politiques et militaires qui n'étaient pas d'origine soudanaise. L'administration anglo-égyptienne établie en 1899 fut ainsi communément appelée la « seconde Turkiyya »par opposition à la « première Turkiyya » qui se réfère à la période 1820-1885. D’où une confusion possible produite par l'exhortation de S.A.R. à lutter contre les «Turcs » durant la première guerre mondiale.

21. Pour plus de détails sur "I'épée de la victoire », cf. Ibrahim, Sayyid “Abd al-Rahmân al-Mahdî, p. 80, note 44 . 
tien et son corollaire idéologique de I'unité de la vallée du Nil. ${ }^{22}$ Cependant, George $\mathrm{V}$ rendit l'épée à S.A.R. en lui disant :

« J'accepte cette épée et je reconnais la loyauté sincère que reflète ce présent. [...] Je prends cette épée et vous la donne, à vous et à vos héritiers, afin que vous défendiez en mon nom mon trône et l'Empire ». ${ }^{23}$

Les postures des deux parties révèlent une rupture majeure par rapport au passé, représentée par la nouvelle charge symbolique de l'épée. D'un outil de lutte contre les Turco-Égyptiens et les Britanniques au temps de la Mahdiyya, elle devenait une arme prête à défendre l'Empire britannique une génération plus tard. En contrepartie, le Roi reconnaissait officiellement le néo-Mahdisme en tant qu'institution et doctrine, malgré les réticences des administrateurs britanniques du Soudan. ${ }^{24}$ Au niveau patrimonial, l'épée se transformait d’un héritage familial en un patrimoine mahdiste coloré d'une teinte nationale. S.A.R. adoptait en effet la position d'un leader national lorsqu'il assura à ses interlocuteurs britanniques que les «véritables aspirations nationales » de la plupart des Soudanais correspondaient à l'indépendance du Soudan. ${ }^{25}$

Politicien habile, S.A.R. épousa à l'égard de la Mahdiyya une attitude qui reflète l'évolution des champs d'application du patrimoine évoquée plus haut. D'une part, le fils du Mahdî conçut la Mahdiyya comme un patrimoine national à même de servir d'instrument à ses ambitions politiques. D'autre part, il semble avoir appréhendé le leadership politico-religieux du mouvement comme un héritage purement familial. II importe de remarquer qu'en 1885, le Mahdî dénonça publiquement les Ashrâf (ses proches) à la mosquée d'Omdurman, les accusant de vouloir usurper le pouvoir comme si «la

22. Warburg, "From revolution to conservatism », p. 108.

23. Extrait de The Times daté du 29 juillet 1919, cité par Graham F. Thomas, Sayed Abd el-Rahman al-Mahdi: a Pictorial Biography, 1885-1959, Londres, Lama Publishing, 1986, p. 79. Ma traduction.

24. Hassan Ahmed Ibrahim, Introduction à al-Mahdî, Mudhakkarât, p. 7.

25. Gabriel R. Warburg, Islam, Sectarianism and Politics in the Sudan since the Mahdiyya, Londres, C. Hurst \& Co, 2002, p. 85-6. Les occasions où S.A.R. se posa en leader et représentant de la nation soudanaise ne manquent pas. À titre d'exemple, il se rendit en Grande Bretagne pour discuter le sens du traité anglo-égyptien de 1936, qui fixait comme objectif principal de l'administration anglo-égyptienne «le bien-être des Soudanais » et reportait la question de la souveraineté à vingt ans plus tard. Cf. Muddathir 'Abd al-Rahîm, Imperialism and Nationalism in the Sudan: a Study in Constitutional and Political Development, 1899-1956, Oxford, Clarendon Press, 1969, 120, p. 250 ; 'Abd al-Rahmân 'Alî Taha, al-Sûdân li-l-sûdâniyyîn: tamac fa-nizâc wa-wathba fa-jihâd. Edité par Fadwa 'Abd al-Rahmân 'Alî Taha, Khartoum, dâr jâmicat al-Khartûm li-l-nashr, 1992, p. 57. 
Mahdiyya [n'appartenait] qu'à eux seuls $»{ }^{26}$ Opposé à tout privilège lié à la parenté, il réussit effectivement à se faire succéder par le Khalîfa cAbdullâhi al-Tacâîshî, avec qu'il n'avait aucun lien familial. Or, la question de la succession à l'imamat demeura cruciale tout au long de l'évolution du mouvement néo-mahdiste. Avec S.A.R. à sa tête, le pouvoir politique et religieux revint dans la famille du Mahdî dès 1914 pour ne plus la quitter jusqu'à nos jours.

Comment S.A.R. légitima-t-il sa position d'imâm des Ansâr? Conscient $d^{\prime}$ une contradiction entre sa position et celle de son père, il mobilisa certaines notions soufies pour montrer que l'imamat n'est pas réductible à une charge héréditaire. Une lumière émanant de I' « abondance prophétique » (al-fayd al-nabawî) guidait le Mahdî et lui fut transmise, l'inscrivant dans une filiation de type spirituel. ${ }^{27}$ L'idéologie néo-mahdiste semble avoir repris cette idée en justifiant le leadership de S.A.R. à travers la baraka du Mahdî (bénédiction divine). ${ }^{28}$ Cependant, le petit-fils de S.A.R., al-Sâdiq al-Mahdî, actuel imam des Ansâr et président du parti Umma ${ }^{29}$, favorise une explication plus pragmatique. Selon lui, son grand-père occupa la fonction d'imam car les trois khulafâ' du Mahdî avaient tous péri dans des combats contre les forces angloégyptiennes. ${ }^{30}$ Dans I'arène politico-religieuse du Soudan indépendant, la succession à l'imamat des Ansâr sur une base filiale fut légitimée par une partie des adhérents au mouvement. ${ }^{31}$ Cependant, des voix contestatrices ne tardèrent pas à se faire entendre. À la suite d'un schisme politique qui divisa la famille

26. Ernst L. Dietrich. "Der Mahdi Mohamed Ahmed vom Sudan nach Arabischen Quellen », Der Islam, Vol. 24, 1925, cité par Peter M. Holt, The Mahdist State in the Sudan 1881-1898, Londres, Oxford University Press, 1970, p. 137.

27. Nicole Grandin, « Al-Sayyid 'Abd al-Rahmân al-Mahdî (1885-1959) et I'héritage mahdiste au Soudan oriental » in Jean-Pierre Digard (éd.), Le cuisinier et le philosophe. Hommage à Maxime Rodinson, Paris, Maisonneuve et Larose, 1982, p. 223. 28. Warburg, Islam, Sectarianism and Politics, p. 103.

29. Le parti Umma fut fondé en 1945 par S.A.R. pour réaliser I'objectif d'un Soudan indépendant préservant des relations amicales avec l'Égypte et la Grande Bretagne. Le terme Umma renvoie à deux idées motrices du mouvement néo-mahdiste : la communauté des musulmans et la nation moderne. Cf. Ibrahim, Sayyid ${ }^{c}$ Abd al-Rahmân al-Mahdî, p. 166, note 1 .

30. Warburg, Islam, Sectarianism and Politics, p. 170. La quasi totalité des frères de S.A.R. moururent dans les combats ou des suites de maladies contractées en prison, au cours des premières années du Condominium. 'Alî fut le seul frère qui survécut sous le Condominium. Cf. Thomas, Sayed Abd el Rahman al Mahdi et Grandin, "Al-Sayyid cAbd al-Rahmân al-Mahdi », p. 218, note 4.

31. Cf. par exemple Amîn al-Tûm, dhikrayât wa-mawâqif fî tarîq al-haraka al-wataniyya al-sûdâniyya, 1914-1969, Khartoum, dâr jâmicat al-Khartûm li-I-nashr, 1987, p.177 pour la succession d'al-Siddîq à S.A.R. en 1959. 
du Mahdî au cours des années 1960, le politicien du parti Umma Muhammad Ahmad Mahjûb constata amèrement que les membres de cette famille «semblent considérer le contrôle de l'État comme un butin qui doit être hérité et divisé entre eux à l'exclusion d'autres membres du parti [Umma] n'appartenant pas à la famille du Mahdî ». ${ }^{32}$

Ainsi, le leadership politique et religieux de la mouvance néo-mahdiste $s^{\prime}$ affirma tout au long du XXe siècle comme un patrimoine familial au sens étroit de la notion. La perpétuation de ce pattern patrimonial jusqu'à aujourd'hui n'a cessé de provoquer de vives réactions au sein du parti Umma, dont certains membres critiquent non seulement I'hégémonie des descendants du Mahdî, mais également la fusion des pouvoirs politique et religieux qu'incarne le leader al-Sâdiq al-Mahdî. ${ }^{33}$ Par ailleurs, il conduisit les Islamistes du NIF (National Islamic Front) à associer le mouvement néo-mahdiste à une dynastie réactionnaire incapable de diriger un État islamique moderne. Les dirigeants islamistes ont, au cours des dernières décennies, insisté sur le fait qu'ils ne devaient leur position qu'à leur charisme et à leurs compétences intellectuelles, et non pas à un quelconque héritage. ${ }^{34}$

En tant que "prophète auto-proclamé du nationalisme soudanais ${ }^{35}$, S.A.R. appréhenda la Mahdiyya comme un turâth (système de valeurs et pratiques religieuses) dont il devait certes s'inspirer, mais qu'il devait ajuster aux circonstances sociales, politiques et économiques du Soudan anglo-égyptien. Le fait que le mouvement néo-mahdiste s'appuyait sur une variété croissante de groupes porteurs d'intérêts parfois antagonistes (nomades et agriculteurs de I'ouest, riverains du nord et du centre, cheikhs villageois et tribaux, intelligentsia émergente) contraignit le leader à développer une stratégie différentialiste qui puisse correspondre à diverses sensibilités. Nous suivons l'analyse de Nicole Grandin lorsqu'elle distingue deux grandes orientations de l'action politique, religieuse et économique de S.A.R. : aux Ansâr urbains et riverains il offrit « une nouvelle idéologie intégrant la modernité coloniale ${ }^{36}$ qui permettait d'adapter les fondements religieux de la Mahdiyya au projet politique moderne du nationalisme. Face à ses supporters du Soudan occidental,

32. Muhammad Ahmad Mahjûb, Democracy on Trial, Reflections on Arab and African Politics, Londres, André Deutsch, 1974, p. 224. Ma traduction.

33. J'ai pu m'en rendre compte lors d'entretiens personnels avec des membres du parti Umma à Omdurman, février-mars 2007.

34. Gabriel R. Warburg, "Mahdism and Islamism in Sudan », International Journal of Middle East Studies, Vol. 27, 2, 1995, p. 233-4.

35. Cette qualification apparaît dans un mémorandum britannique daté du 28 avril 1935, rédigé par un employé de la Public Security Intelligence. Cf. Ibrahim, Sayyid ${ }^{c}$ Abd al-Rahmân al-Mahdi , p. 138, note 6, p. 145.

36. Grandin, "Al-Sayyid cAbd al-Rahmân al-Mahdî ». 
S.A.R. mit en évidence la continuité religieuse - notamment rituelle - entre le Mahdisme et le néo-Mahdisme.

En ce qui concerne la première orientation, nous pouvons mentionner trois exemples qui montrent clairement la capacité de S.A.R. à s'attaquer à des piliers de la Mahdiyya afin qu'ils se conforment au moule de ses ambitions politiques. D'abord, le contenu du serment d'allégeance (bay a) fut modifié de façon à légaliser l'accumulation de richesses qui, selon S.A.R., représentait une nécessité nationale incontournable sur le chemin de l'indépendance. ${ }^{37}$ Ensuite, le devoir du djihad, qui sous le Mahdî avait acquis une plus grande importance que le pèlerinage (hajj), fut réinterprété par S.A.R. pour des motifs pragmatiques. Il le définit comme jihâd al-nafs (lutte intérieure) et souligna que des efforts pacifiques pouvaient produire les mêmes résultats qu'une action guerrière. ${ }^{38}$ Enfin, S.A.R. accentua la dualité de sa mission : elle était à la fois spirituelle (purification de I'Islam et unification des vrais croyants) et temporelle (combat politique pour l'indépendance nationale du Soudan). Ainsi, il parvenait à inscrire sa mission dans la lignée de celles du Mahdî et du Prophète tout en y insérant une facette politique éminemment moderne : les attentes eschatologiques de la Mahdiyya avaient fait place au projet national des indépendantistes.

Quant au second aspect de la stratégie de S.A.R., il consistait à maintenir des pratiques collectives mahdistes en dépit de leur interdiction par le régime colonial britannique. Les rituels qui nourrissaient la vie spirituelle du mouvement néo-mahdiste comprenaient la bayca, la lecture du râtib ${ }^{39}$ (livre de prière du Mahdî) et des manchûrât (proclamations du Mahdî), ainsi que le respect de règles de prière particulières. D'autres pratiques servaient à renforcer l'assise

37. Warburg, Islam, Sectarianism and Politics, p. 101. Au temps du Mahdî, la bay ca incluait une renonciation aux biens de ce monde. Toutes les entreprises faiseuses de profits (banques, magasins) devaient être regroupées sous la tutelle du bayt al-mâl (trésor public).

38. Ibid., p. 102 ; Grandin, "Al-Sayyid 'Abd al-Rahmân al-Mahdi », p. 225 ; Peter Woodward, "Islam, Radicalism and Nationalism in Sudanese Politics before Independence » in Gabriel R. Warburg et Uri M. Kupferschmidt (éds.), Islam, Nationalism and Radicalism in Egypt and the Sudan, New York, Praeger, 1983, p. 99. Selon M. A. Mahjûb, S.A.R. avait pris conscience de la faiblesse militaire des Ansâr, $\mathrm{C}^{\prime}$ est pourquoi il opta pour la collaboration avec les Britanniques comme stratégie de survie du mouvement.

39. En 1924, S.A.R. encouragea la publication de 5000 exemplaires du râtib. Bien que les administrateurs britanniques eussent initialement prohibé la lecture et la diffusion de cet ouvrage, leur position devint remarquablement plus vague et indécise au cours des années 1917-1921. Ils réalisèrent ensuite qu'il leur était impossible d'arrêter la vente du livre. Cf. Ibrahim, Sayyid c Abd al-Rahmân al-Mahdi , p. 78-9. 
matérielle du mouvement, notamment la zakât (aumône), la réduction de la dot et le pèlerinage des Ansâr à l'île d'Aba. ${ }^{40}$

\section{DES MODALITÉS DE PATRIMONIALISATION SOCIALES ETINTELLECTUELLES}

Le processus de patrimonialisation nationale de la Mahdiyya n'était pas I'apanage de S.A.R. II impliquait également d'autres acteurs qui, à travers des conduites sociales ou des postures historiographiques particulières, renforcèrent le statut patrimonial de la Mahdiyya et lui accordèrent un rôle prépondérant dans la formation du nationalisme soudanais. N'étant pas en mesure de développer amplement ce point dans l'espace limité de cet article, nous en signalerons quelques exemples marquants. Berceau de la prédication mahdiste, l'île d'Aba devint le centre spirituel, social et économique du mouvement néo-mahdiste dès la fin de la première guerre mondiale. Selon les termes de S.A.R., Aba "réunit les Ansâr autour de l'enseignement religieux et la restauration du patrimoine [turâth] de leurs ancêtres [...] ». ${ }^{41}$ Un nombre croissant de migrants originaires du Soudan occidental et d'Afrique de I'ouest (fallata) convergeaient chaque année vers l'île pour y effectuer un pèlerinage ou $s^{\prime} y$ installer durablement, travaillant sur les exploitations agricoles de S.A.R. ${ }^{42}$ À partir de 1921, celui-ci organisa une parade annuelle à I'occasion du Ramadan, qui rassemblait plusieurs milliers d'Ansâr. Ainsi, outre son rôle historique fondateur -en tant que lieu de naissance du Mahdisme et de la nation soudanaise-, I'île d'Aba acquérait une fonction moderne essentielle en tant que patrimoine reconnu et revivifié par l'action collective des pèlerins.

Dans la sphère politique et historiographique, des intellectuels soudanais contemporains de S.A.R. contribuèrent à transformer la Mahdiyya en patrimoine national soudanais. Conscients du fait que l'État mahdiste du XIXe siècle représentait un support légitimant la revendication d'un Soudan indépendant, les dirigeants néo-mahdistes développèrent une conception selon laquelle le Mahdî était le "premier nationaliste soudanais $»{ }^{43} \mathrm{C}^{\prime}$ est par ce biais que S.A.R. parvint à attirer dans son orbite des individus qui, sans être des Ansâr,

40. Grandin, "Al-Sayyid 'Abd al-Rahmân al-Mahdî », p. 225.

41. Al-Mahdî, Mudhakkarât, p. 35. Ma traduction.

42. Warburg, Islam, Sectarianism and Politics, p. 92-3; Ibrahim, Introduction à alMahdî, Mudhakkarât, p. 7. Pour plus de détails sur les entreprises agricoles de S.A.R. sur I'île d'Aba, cf. Ibrahim, Sayyid ' ${ }^{\circ}$ bbd al-Rahmân al-Mahdî , p. 68, p. 118-9.

43. Voll, «Mahdis, Walis and New Men », p. 377. 
soutenaient le projet indépendantiste. Tel était par exemple le cas du politicien et intellectuel nationaliste M. A. Mahjûb évoqué plus haut. ${ }^{44}$

Dans son avant-propos aux mémoires de S.A.R., Mahjûb dépeint la Mahdiyya comme un mouvement révolutionnaire unique qui vainquit les dominations européenne et ottomane malgré sa faiblesse technologique. La « reconquête » anglo-égyptienne du Soudan devient sous sa plume un long conflit armé durant lequel la résistance soudanaise fut exemplaire. Qualifiant les combattants mahdistes de "forces armées nationales [wataniyya] » ${ }^{45}$, il souligne qu'ils étaient prêts à sacrifier leur vie. Mais pour quelle cause ? Bien que Mahjûb ne le précise pas, la terminologie qu'il emploie (tadhiyya, chahâda, fidâ') crée l'impression d'un flottement sémantique entre le martyre religieux (résultant du djihad) et le sacrifice national (mourir pour la patrie).

Les écrits d'Amîn al-Tûm -journaliste, politicien du parti Umma et associé de longue date de S.A.R.- témoignent également d'une patrimonialisation nationale de la Mahdiyya, bien que d'une façon plus détournée. Ils célèbrent le Mahdî comme

" le libérateur du Soudan, le bâtisseur de sa gloire et de son honneur,

l'initiateur de la grande révolution islamique ». ${ }^{46}$

Considérée comme un âge glorieux, la Mahdiyya est associée à une période formative du nationalisme soudanais, puisque $c^{\prime}$ est elle qui a produit des générations ayant œuvré pour l'indépendance du Soudan.

Notre cheminement réflexif nous a permis de cerner différentes modalités selon lesquelles la Mahdiyya fut transformée en patrimoine national soudanais durant le Condominium. Les postures politiques et symboliques de S.A.R., les rituels néo-mahdistes collectifs ainsi que les lectures nationalistes de la Mahdiyya concoururent à ce processus. Cependant, motivées par des objectifs d'ordre politique, idéologique ou scientifique, des forces d'origines très diverses oeuvrèrent à la même période contre cette patrimonialisation nationale. II convient donc d'examiner comment ces acteurs s'efforcèrent de dé-patrimo-

44. Muhammad Ahmad Mahjûb (1905-1976) reçut une formation d'ingénieur, (Gordon College), puis de droit. Figure prééminente du camp nationaliste indépendantiste, il contribua aux journaux soudanais al-Hadâra et al-Nahda. Membre du parti Umma, il représenta la tendance indépendantiste auprès de I'ONU en 1947 et participa à la première assemblée législative du Soudan un an plus tard. Après l'indépendance, il occupa plusieurs postes ministériels (Affaires Étrangères, Défense, Premier Ministre) jusqu'en 1969. Cf. Afaf Abdel Majid Abu Hasabu, Factional Conflict in the Sudanese Nationalist Movement, 1918-1948, Khartoum, Graduate College, University of Khartoum, 1985, p. 171.

45. Muhammad Ahmad Mahjûb, «Avant-propos » à al-Mahdî, Mudhakkarât, p. 22. 46. Al-Tûm, dhikrayât wa-mawâqif, p. 176. Ma traduction. 
nialiser ou de contre-patrimonialiser la Mahdiyya, que ce soit par l'effacement de traces matérielles, l'élaboration d'un contre-modèle patrimonial, la mise en évidence d'une expérience collective négative ou la réflexion historique.

\section{UN CONTRE-MODÈLE PATRIMONIAL BRITANNIQUE}

Au tournant du $X X^{e}$ siècle, le projet britannique de "reconquête " du Soudan ne se limitait ni à une occupation territoriale du pays, ni à l'établissement $d^{\prime}$ une administration de type colonial. La mise en place d'un système de domination effectif exigeait non seulement l'élimination matérielle et institutionnelle du régime mahdiste, mais également l'effacement de toute trace évocatrice de la Mahdiyya. Outre le massacre de nombreux Ansâr lors des batailles de Kararî et d'Umm Dibaykrât ${ }^{47}$, le bombardement de la coupole

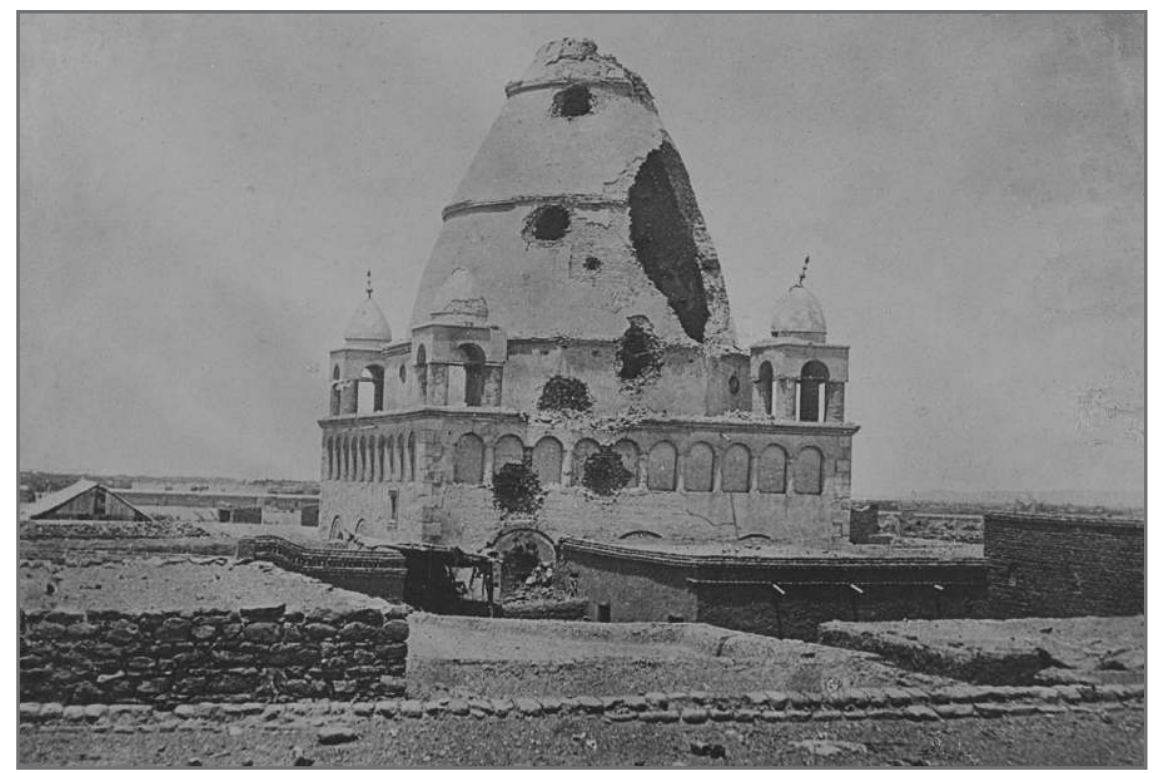

1. La tombe du Mahdî bombardée par les forces britanniques après la bataille d'Omdurman (3 septembre 1898). Reproduction autorisée par la bibliothèque de I'Université de Durham, SAD $1 / 22 / 68$.

47. A Kararî (2 septembre 1898) le nombre de victimes mahdistes s'éleva à environ 10800 morts et 16000 blessés, pour 48 morts et 386 blessés anglais. Hervé Bleuchot, "Le Soudan au XIX siècle » in Marc Lavergne, Le Soudan contemporain : de l'invasion turco-égyptienne à la rébellion africaine (1821-1989) Paris, Karthala CERMOC, 1989, p. 167. 
du Mahdî, la destruction de son tombeau et la dispersion de ses cendres dans les eaux du Nil représentaient I'annihilation physique et symbolique du Mahdisme. Une logique similaire sous-tend le traitement que les Britanniques réservèrent au Khalîfa Muhammad Charîf (beau-fils du Mahdî et figure centrale de l'élite mahdiste) et aux deux fils du Mahdî al-Fâdil et al-Buchra. Fusillés en 1899 à al-Chukâba, leurs corps furent jetés dans le Nil. Bien qu'émanant du leader de la renaissance mahdiste, cette réflexion ne nous semble pas dépourvue de pertinence :

«Les autorités [britanniques] voulaient peut-être qu'ils n'aient pas de

tombes visitables $»{ }^{48}$

En supprimant les traces matérielles d'une existence mahdiste humaine, le nouveau régime annulait la possibilité $d^{\prime}$ une patrimonialisation nuisible à ses propres intérêts stratégiques.

Les efforts britanniques de dé-patrimonialisation de la Mahdiyya se poursuivirent sous le règne de Wingate (gouverneur général de 1900 à 1916). Largement influencée par l'inspecteur général Slatin Pacha ${ }^{49}$, la politique du régime colonial visait à détruire le leadership mahdiste et à empêcher la patrimonialisation spirituelle de la Mahdiyya. Parmi les mesures répressives adoptées par Wingate, signalons l'emprisonnement des émirs mahdistes et de leurs familles, l'interdiction de lire le râtib et les manchûrât, ainsi que l'interdiction d'effectuer des pèlerinages vers les lieux « sacrés » du Mahdisme. Ceux-ci comportaient notamment la grotte dans laquelle la mission de Muhammad Ahmad lui aurait été révélée (al-ghâr) et les montagnes de Qâdir, où il aurait reçu le râtib. ${ }^{50}$

En parallèle à une action destinée à contrecarrer la patrimonialisation de la Mahdiyya, le pouvoir britannique entreprit l'élaboration active de ce que I'on peut qualifier de « contre-modèle patrimonial ». Celui-ci permettait de délégi-

48. Al-Mahdî, Mudhakkarât, p. 33. Ma traduction.

49. D'origine autrichienne, Rudolf Carl von Slatin (1857-1932) avait travaillé pour le gouvernement turco-égyptien (1878-1884) notamment en tant que gouverneur du Darfour. De 1884 à 1895, il fut détenu à Omdurman comme prisonnier de l'État mahdiste. Après sa fuite du Soudan, il exerça la fonction d'assistant directeur des Services de Renseignements égyptiens. Sous le Condominium anglo-égyptien, affublé du grade de pacha, il servit d'inspecteur général de 1900 à 1914. Rendu amer par sa longue captivité, il chercha à supprimer le Mahdisme et à humilier ses dirigeants. Cf. Ibrahim, Sayyid 'Abd al-Rahmân al-Mahdî, p. 66.

50. Ibid. ; Muhammad Ibrâhîm Abû Salîm, « al-Sayyid 'Abd al-Rahmân wa-imâmat al-Ansâr » in Yûsuf Fadl Hasan, Muhammad Ibrâhîm Abû Salîm et al-Tayyeb Mîrghanî Shakkâk, (éds.), al-imâm 'Abd al-Rahmân al-Mahdî : mudâwalât al-nadwa al-cilmiyya li-l-ihtifâl al-mi'awî, Le Caire, maktabat madbûlî, 2002, p. 115. 
timer le schéma patrimonial mahdiste tout en légitimant la présence impériale britannique au Soudan. En quoi consistait-il ? La première facette de ce contremodèle mit en évidence les trophées de guerre des forces anglo-égyptiennes victorieuses. Au-delà des biens matériels pris au camp mahdiste, certaines représentations visuelles concoururent à accentuer le caractère misérable et repoussant des vaincus. Les photographies qui immortalisèrent la dévastation du tombeau du Mahdî par les cannons britanniques et qui dévoilèrent les cadavres du Khalîfa 'Abdullâhi et de ses partisans sur le champ de bataille remplirent cette fonction tout en donnant à voir des preuves incontestables de l'échec mahdiste (cf. fig. 1, 2 et 3).51

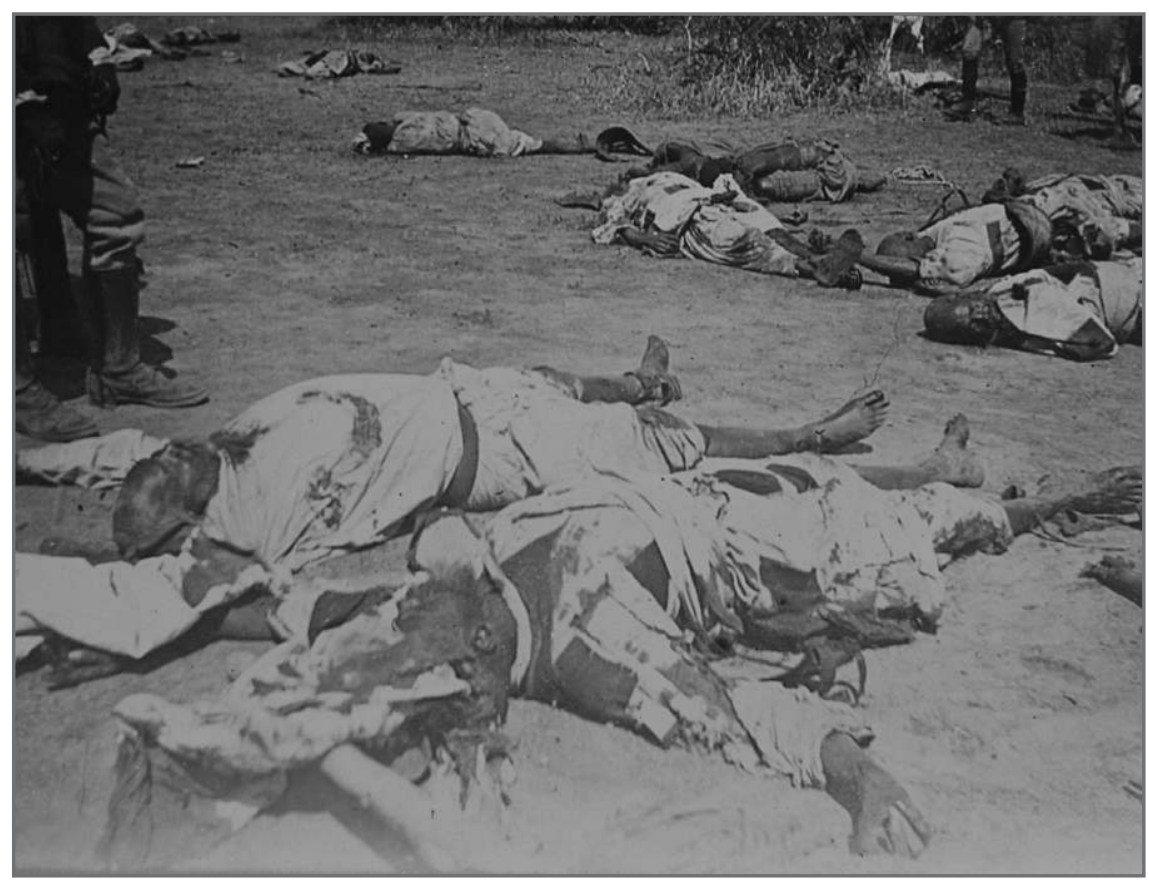

2. Cadavres du Khalîfa 'Abdullâhi (à gauche) et de l'émir Ahmad Fâdil gisant sur le champ de bataille d'Umm Dibaykrât (24 novembre 1899). Reproduction autorisée par la bibliothèque de I'Université de Durham, SAD 621/6/2.

51. Cf. Heather J. Sharkey, Living with Colonialism: Nationalism and Culture in the Anglo-Egyptian Sudan, Berkeley, University of California Press, 2003, 56; Thomas, Sayed Abd el Rahman al Mahdi, p. 82, p. 86 ; et les annexes de Viviane A. Yagi, Khalifa Abdullahi : sa vie et sa politique. Thèse de doctorat en histoire et civilisation, Montpellier III, Université de Lille, 1990, 2 tomes. Le gouvernement du Soudan ne permit à S.A.R. de reconstruire le tombeau de son père qu'en 1946, à ses propres frais. 


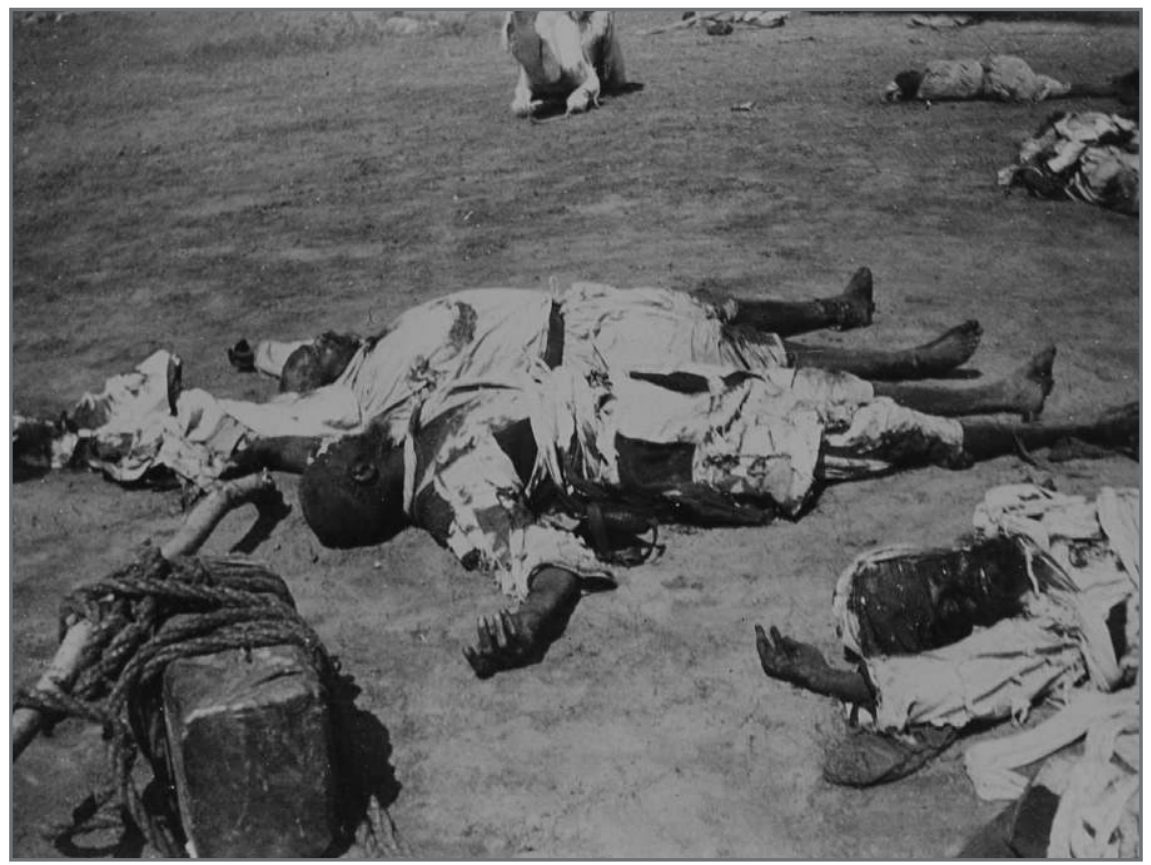

3. Cadavres du Khalîfa 'Abdullâhi et de l'émir 'Alî wad Hilû gisant sur le champ de bataille d'Umm Dibaykrât, près d'une réserve de munitions (24 novembre 1899). Reproduction autorisée par la bibliothèque de l'Université de Durham, SAD 621/6/4.

La seconde facette du contre-modèle britannique se construisit autour de la sacralisation mémorielle du général Charles George Gordon (1833-1885).52 Tué par les forces mahdistes lors de la prise de Khartoum en janvier 1885, cet officier profondément croyant vint à incarner l'archétype du martyre dans la mythologie de la communauté britannique du Soudan..$^{53}$ Le souvenir de sa mort héroïque contribua à rallier l'opinion publique anglaise au projet de "reconquête » du Soudan. Au cours du Condominium, la figure de Gordon

52. Gordon servit le régime turco-égyptien en tant que gouverneur de la province d'Equatoria (1874-1876) et gouverneur général du Soudan (1877-1880). En 1884, le gouvernement britannique l'envoya au Soudan pour étudier la meilleure façon d'évacuer les troupes turco-égyptiennes prises d'assaut par les forces mahdistes. Entre mars 1884 et janvier 1885, il organisa la défense de Khartoum contre le siège mahdiste.

53. Peter Woodward, "In the Footsteps of Gordon: the Sudan Government and the Rise of Sayyid Sir Abd al-Rahman al-Mahdi, 1915-1935 », African Affairs, Vol. 84, 334, 1985, p. 39. 
fit l'objet d'un processus de sacralisation qui s'adressait tant au public britannique que soudanais (cf. fig. 4). ${ }^{54}$

Des institutions publiques furent ainsi établies à son nom. Fondé à Khartoum en 1902, le Gordon Memorial College avait pour mission de former une élite soudanaise composée de bureaucrates, de comptables, d'enseignants, d'ingénieurs et de qadis. ${ }^{55}$ Une cathédrale anglicane fut consacrée en 1912 comme un mémorial en l'honneur du général. En Grande Bretagne et en Australie, de nombreux lieux publics furent baptisés à son nom : écoles, instituts scientifiques, promenades et places publiques, parcs et quartiers urbains. Un bombardier et une ligue de rugby britanniques furent même inclus dans cette entreprise mémorielle et patrimoniale. ${ }^{56}$

L'élaboration d'un modèle patrimonial opposé à celui de la Mahdiyya s'effectua également à travers des rituels collectifs de commémoration. En janvier 1935, le gouvernement du Soudan organisa une série d'événements pour marquer le cinquantième anniversaire de la mort de Gordon. Un culte spécial eut lieu à la cathédrale anglicane, suivi d'une parade militaire devant la statue du général, qui mobilisa une cinquantaine d'anciens soldats ayant combattu à ses côtés. Le plus célèbres des bateaux de la flotte de Gordon, le Bordein, fut rénové et exposé sur le quai attenant au palais du gouverneur général. ${ }^{57}$ La commémoration officielle de son martyre héroïque ajoutait une teinte émotionnelle au narrative impérial servi à tous les nouveaux employés de I'administration britannique au Soudan. Dès leur arrivée, ceux-ci étaient « complètement immergés dans les atrocités de l'État mahdiste, desquels la reconquête anglo-égyptienne, culminant avec la victoire de Kitchener à Omdurman, avait libéré les peuples opprimés du Soudan. ${ }^{58}$ Les esprits des

54. Le régime colonial britannique tenta de s'attirer la sympathie des populations soudanaises en présentant la Mahdiyya comme une tyrannie oppressive et fanatique contre laquelle Gordon avait essayé de prémunir le Soudan. Cf. Norman Daniel, Islam, Europe and Empire, Edinburgh, Edinburgh University Press, 1966, p. 416, p. 445-446; Yûsuf Fadl Hasan, Some Aspects of the Writing of History in Modern Sudan, Khartoum, Khartoum University Press, 1978, p. 12.

55. Sharkey, Living with Colonialism, 7. Le collège vit l'émergence d'une classe soudanaise instruite destinée à servir l'administration coloniale. Au grand dam des Britanniques, il fut également le creuset du nationalisme soudanais.

56. Cf. Wikipedia, "Charles George Gordon », 15 octobre 2007 [en ligne]

http://en.wikipedia.org/wiki/Charles_George_Gordon, 27 octobre 2007. Au sujet des statues élevées à son effigie à Londres, 1889, et à Khartoum, 1902, cf. C.R. Wilson, Royal Engineers Museum, "Major General Charles George GORDON, 1833-1885», 5 août 2006 [en ligne], http://www.remuseum.org.uk/rem_his_bio.htm\#null,27 octobre 2007.

57. Woodward, «In the Footsteps of Gordon », p. 39.

58. Ibid., p. 40. Ma traduction. 


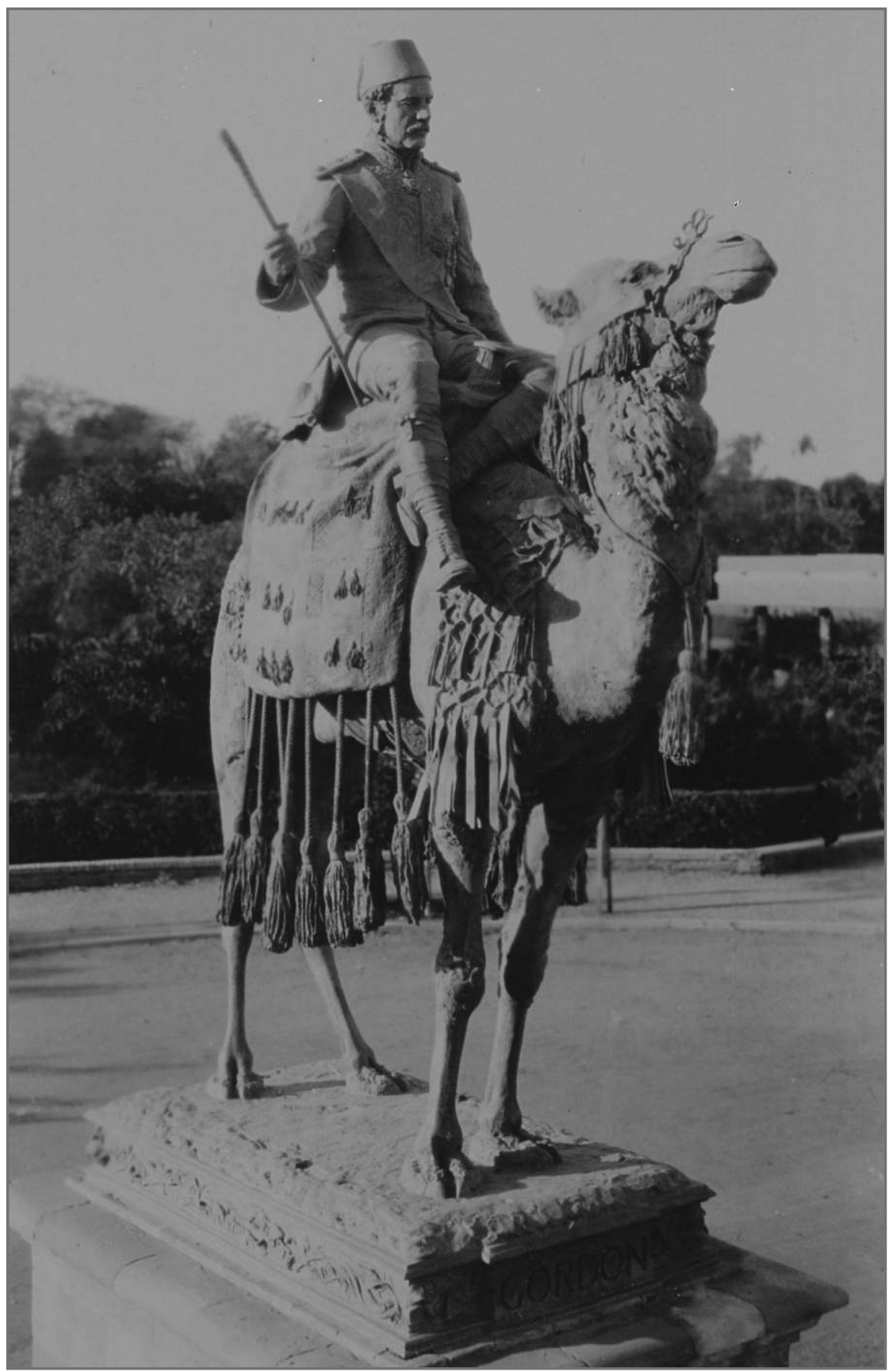

4. Statue de Gordon, conçue par Onslow Ford et érigée à Khartoum en 1902 (date de la photographie : env. 1931-1940). Reproduction autorisée par la bibliothèque de I'Université de Durham, SAD 302/15/27. 
agents coloniaux étaient ainsi imprégnés des horreurs et des gloires du passé, qui concouraient à entretenir la crainte d'un renouveau mahdiste tout en couronnant d'une aura légitimatrice la domination britannique du Soudan.

\section{UN RIVAL POLITICO-IDÉOLOGIQUE : L'UNITÉ DE LA VALLÉE DU NIL}

Les motifs sous-tendant la dé-patrimonialisation et la contre-patrimonialisation de la Mahdiyya par les impérialistes britanniques sont aisément compréhensibles. Ceux qui poussèrent certains nationalistes soudanais à adopter une posture similaire le sont peut-être moins. Rappelons-nous que le nationalisme soudanais se développa, dès la fin de la première guerre mondiale, selon deux orientations idéologiques distinctes: le Soudan aux Soudanais et l'unité de la vallée du Nil. Ces deux courants intellectuels et politiques avaient un impact immédiat sur les relations entre le Soudan, l'Égypte et la Grande Bretagne, comme le montrent par exemple la révolte de 1924 ou les activités du Congrès des Diplômés (Graduates' Congress) fondé en 1938. ${ }^{59}$ En vue de légitimer leurs revendications politiques respectives, les nationalistes des deux bords élaborèrent différentes conceptions du passé historique, lointain ou récent. C'est ainsi que les Unionistes, de par leurs contacts étroits avec les milieux nationalistes égyptiens, épousèrent nombre d'idées relatives à la continuité historique de la vallée du Nil en tant qu'entité géographique, politique, économique et culturelle. Bien qu'ils aient privilégié I'Islam et I'arabisme comme principes d'unité jusqu'aux années 1930, un petit nombre d'entre eux s'intéressa subséquemment aux aspects préislamiques ou non islamiques du Soudan. ${ }^{60}$

Qu'ils fussent sincèrement convaincus de la nécessité d'une union égyptosoudanaise ou qu'ils aient conçu l'idéologie de l'unité de la vallée du Nil comme un outil provisoire permettant de combattre efficacement I'impérialisme britannique, les Unionistes avaient intérêt à contrecarrer la transformation de la Mahdiyya en patrimoine national soudanais. Le Mahdisme était en effet associé à un mouvement politique rival, qui de surcroît collaborait avec l'en-

59. Pour plus de détails sur la révolte populaire initiée par la Ligue du Drapeau Blanc (White Flag League) en signe de protestation contre l'exclusion des Soudanais des pourparlers anglo-égyptiens touchant au statut du Soudan, cf. Mahâsin 'Abd al-Qâdir Hâjj al-Sâfî, al-haraka al-wataniyya fî-l-Sûdân, thaurat 1924, Khartoum, matbacat jâmicat al-Khartûm, 1992; 'A Abd al-Rahîm, Imperialism and Nationalism, p. 102-108. Au sujet du Congrès des Diplômés, cf. ibid., p. 124-132.

60. 'Abd al-Rahîm, « Arabism, Africanism and Self-Identification », p. 243-5. Cet intérêt pour un passé antéislamique peut être comparé au Pharaonisme égyptien, même s'il prit des proportions sensiblement moins importantes au Soudan qu'en Égypte. 
nemi britannique. Les Unionistes condamnèrent la Mahdiyya comme le règne d'une escroquerie religieuse et une expérience historique essentiellement négative. Divers secteurs de la population soudanaise pouvaient s'identifier à cette représentation, puisque le mouvement mahdiste avait soulevé des oppositions et des critiques dès son apparition. Alors que nombre d'ulémas soudanais formés à al-Azhar n'avaient jamais reconnu Muhammad Ahmad en tant que Mahdî, les dirigeants des confréries soufies (turuq) avaient eu tendance à le percevoir comme un danger à leur propre influence. ${ }^{61}$ De plus, le souvenir de la Mahdiyya était fréquemment associé à de mauvaises expériences et à des temps difficiles. Certains avaient souffert des restrictions puritaines imposées par les lois mahdistes, tandis que d'autres avaient déploré l'incapacité du Khalîfa cAbdullâhi à maintenir les standards religieux établis par son prédécesseur. ${ }^{62}$ Le favoritisme tribal et le clientélisme caractéristiques de sa politique avaient aliéné une grande partie de ses sujets, notamment les riverains du Nil. Enfin, les famines et les épidémies qui avaient ravagé le Soudan sous son règne n'améliorèrent pas l'image de la Mahdiyya telle qu'elle fut retenue dans les mémoires soudanaises.

En outre, les Unionistes procédèrent à une délégitimation systématique de leur principal rival politique, le parti Umma. Leur stratégie discursive comportait trois facettes distinctes, bien que liées. Ils accusèrent d'abord le parti de n'être autre qu'une création du gouvernement britannique destinée à promouvoir ses intérêts impérialistes. ${ }^{63}$ Ils le présentèrent ensuite comme I'instrument des ambitions personnelles de S.A.R., qui selon eux rêvait d'éta-

61. Holt, "Sudanese Nationalism», p. 241. Ceci était particulièrement vrai de la Khatmiyya, tarîqa dirigée par la famille Mîrghanî qui avait traditionnellement collaboré avec les autorités turco-égyptiennes. Pour une étude détaillée du développement des turuq au Soudan, cf. 'Alî Sâlih Karrâr, The Sufi Brotherhoods in the Sudan, Londres, C. Hurst \& Co, 1992.

62. Hassan Ahmed Ibrahim, "Mahdist Risings against the Condominium Government in the Sudan, 1900-1927 ", International Journal of African Historical Studies, Vol. 12, 3, 1979, p. 471 ; Holt, «Sudanese Nationalism », p. 241.

63. F.O. 371/45972, Rapport du Secrétaire Civil J. W. Robertson, 8 avril 1945, cité dans Hasan Hamduna Allah Mustafa Hasan, hizb al-Umma al-sûdânî, 1945-1969, Le Caire, charikât sacîd li-I-fann, 1989, p. 198. Robertson démentit cette accusation en interprétant la fondation du parti Umma comme une réaction soudanaise à la « menace égyptienne». 
blir une monarchie mahdiste au Soudan. ${ }^{64}$ Enfin, ils identifièrent I'orientation néo-mahdiste du parti comme une menace à l'encontre de tous ceux qui n'appartenaient pas au groupe des Ansâr. Selon I'usage mahdiste, le terme Umma pouvait en effet être interprété comme une communauté restreinte à ceux qui avaient accepté la mission du Mahdî, tous les autres Musulmans étant associés à des infidèles. ${ }^{65}$ Ce type de propagande renforça de façon décisive le soutien populaire au camp unioniste, qui remporta des succès importants aux élections du Congrès des Diplômés en novembre 1944 ainsi qu'à l'élection du premier parlement soudanais en novembre 1953. ${ }^{66}$

Les conceptions idéologiques et les intérêts politiques respectifs des impérialistes britanniques et des unionistes soudanais les situaient dans des positions fortement antagoniques. Ils partageaient pourtant une vision commune de la Mahdiyya, dont ils se remémoraient les horreurs passées et craignaient la renaissance dans le présent. Les projets des uns comme des autres (un Soudan anglais ou une vallée du Nil unifiée) les amenaient à se dresser contre la patrimonialisation nationale du mouvement mahdiste.

\section{CONCLUSION}

Le statut patrimonial national de la Mahdiyya devint l'enjeu d'une lutte historiographique après I'indépendance du Soudan. Il serait erroné d'imaginer un affrontement entre deux camps bien distincts, opposant des historiens soudanais " patrimonialiseurs » à des historiens non-soudanais " dé-patrimonialiseurs ». L'appartenance nationale s'avère peu utile lorsqu'il s'agit de distinguer les différentes tendances historiographiques. En effet, aussi bien des historiens soudanais qu'occidentaux participèrent -intentionnellement ou non- au processus de patrimonialisation de la Mahdiyya en en faisant un lieu de mémoire central du nationalisme soudanais. 'Abd al-cAzîz Husayn al-Sâwî, Peter M. Holt et John O. Voll exemplifient bien cette orientation. ${ }^{67}$ De I'autre côté, des

64. F. O. 371/45972, Sudan Political Intelligence Summary $n^{\circ}$ 47, février 1945, contenu dans ibid., 193; Philip B. Broadbent, "Sudanese Self-Government », Royal Institute of International Affairs, Vol. 30, 3, 1954, p. 322. Cette idée était répandue parmi les rivaux politiques de S.A.R. ainsi que chez certains administrateurs britanniques. S.A.R. ne réfuta publiquement cette allégation que le 3 août 1953, marquant sa préférence pour un régime républicain au Soudan. Cf. Ibrahim, Sayyid ' $A b d$ alRahmân al-Mahdî, p. 88, note 2 .

65. Holt, «Sudanese nationalism », p. 246.

66. Hasan, hizbal-Umma, p. 196-7; Broadbent, " Sudaneseself-government », p. 321-2. 67. Cf. respectivement ${ }^{\mathrm{C}} \mathrm{Abd}$ al--Azîz Husayn al-Sâwî, hiwârât al-hawiyya wa-I-wahda al-wataniyya fî-I-Sûdân, wijhat nazar mukhtalifa. Le Caire, markaz al-dirâsât al-sûdâniyya, 1994, p. 22, p. 25 ; Holt, «Sudanese nationalism », p. 240-1 ; Voll, « Mahdis, walis and new men », p. 371. 
universitaires soudanais et étrangers contribuèrent à la dynamique de dé-patrimonialisation de la Mahdiyya à travers une réflexion critique sur son rôle dans le développement du nationalisme soudanais. ${ }^{68}$ Issues de la politologie ou de l'histoire, leurs analyses examinent la façon dont les habitants du Soudan concevaient leur identité sociale à différentes périodes. Insistant sur le fait qu'aucune conscience nationale soudanaise n'existait à l'époque mahdiste, ces études concluent que la Mahdiyya ne peut guère être associée à un mouvement nationaliste, ni même à ses ferments. ${ }^{69}$ Son rôle de fondateur ou de précurseur réfuté, la Mahdiyya se voit ainsi dépouillée de son statut patrimonial national.

Les processus de fabrication du patrimoine engendrent parfois des luttes qui ont pour enjeu l'appropriation d'un même objet -matériel ou immatériel- par différents groupes. La revendication d'un lien généalogique avec les descendants du Prophète Muhammad, qui présente une remarquable continuité dans I'ensemble du monde musulman, en constitue peut-être l'un des exemples les plus extrêmes. À l'échelle soudanaise, la Mahdiyya n'entre toutefois pas dans cette catégorie d'objets patrimonialisés. Elle ne fut pas l'enjeu d'un conflit opposant des factions rivales déterminées à se l'approprier en tant que patrimoine. Elle était impliquée dans un autre type de conflit, centré sur la désirabilité et la légitimité mêmes de son statut patrimonial. Alors que certains cherchèrent à le créer ou à le renforcer, d'autres s'efforcèrent de le nier ou de le détruire.

Quelques questions mériteraient d'être explorées de façon approfondie afin de mieux pouvoir apprécier l'apport des approches critiques du patrimoine à la compréhension du Soudan contemporain. L'une d'elles concerne les effets et la portée du processus de patrimonialisation nationale de la Mahdiyya. Au niveau discursif, S.A.R. présenta la Mahdiyya comme le bien collectif de l'ensemble de la population du Soudan. Cependant, quelles portions de la société soudanaise purenteffectivement se reconnaître dans ce patrimoine ?Quoique le mouvement indépendantiste ait inclus des non-Mahdistes tels que M. A. Mahjûb, les Ansâr

68. Cf. notamment Oluwadare Aguda, «Arabism and Pan-Arabism in Sudanese Politics ", Journal of Modern African Studies, Vol. 11, 2, 1973, p. 182; John O. Voll, «The Eastern Sudan, 1822 to Present » in Nehemia Levtzion et Randall L. Pouwels (éds.), The History of Islam in Africa, Ohio, Ohio University Press, 2000, 154. Voll tourne le dos à une lecture nationaliste de la Mahdiyya qu'il proposa au début des années 1970, cf. note précédente; 'Abd al-Rahîm, "Arabism, Africanism and SelfIdentification », p. 238, p. 241 ; Sharkey, Living with Colonialism, p. 18, p. 36-7.

69. Sharkey rapporte à 1927 le premier usage conscient du terme «Soudanais» comme épithète d'une identité nationale. Dans une série d'articles publiés cette année-là par le journal al-Hadâra, le poète Hamza al-Malik Tambal postula l'existence d'une littérature et d'une identité spécifiquement soudanaises. Cf. Heather Sharkey, "A century in Print: Arabic Journalism and Nationalism in the Sudan, 1899$1999 »$, International Journal of Middle East Studies, Vol. 31, 4, 1999, p. 537. 
constituaient-ils finalement la seule entité collective pouvant s'y identifier?

Un second questionnement pourrait s'élaborer autour de S.A.R. en tant qu'artisan du patrimoine lui-même fait patrimoine après sa mort en 1959 . Tandis que de nombreux intellectuels soudanais et occidentaux le dépeignirent comme une figure exceptionnelle de la vie politique, économique, culturelle et religieuse du Soudan colonial, le centenaire de sa naissance fut célébré par un colloque scientifique et l'établissement d'un fonds spécialement conçu comme un mémorial. ${ }^{70}$ Ceci doit-il être interprété comme un signe du caractère mondial de "l'ère de la commémoration "? ?11

Enfin, I'accession du Soudan à l'indépendance en 1956 entraîna l'émergence d'une nouvelle configuration d'acteurs sur la scène politique, qui incluait désormais le Sud-Soudan. ${ }^{72}$ Les tentatives de définition d'une identité nationale soudanaise, confrontées à la multiplicité des revendications identitaires locales, générèrent de nouveaux processus et enjeux patrimoniaux qu'il conviendrait d'examiner. Le Soudan actuel est par ailleurs le théâtre d'une diversification croissante des contenus et des usages du patrimoine. Ceux-ci sont désormais largement impliqués dans les interactions entre le gouvernement central et des zones "périphérialisées» sur les plans politique, économique et culturel.

70. Le colloque donna lieu à une récente publication approchant les sept cents pages : Yûsuf Fadl Hasan, Muhammad Ibrâhîm Abû Salîm et al-Tayyib Mîrghanî Shakkâk (éds.), al-imâm ' ${ }^{`}$ bbd al-Rahmân al-Mahdî : mudâwalât al-nadwa al-cilmiyya li-l-ihtifâl al-mi'awî, Le Caire, maktabat madbûlî, 2002. Au sujet du "Sayed Abd el Rahman Centenary Fund ", cf. Thomas, Sayed Abd el Rahman al Mahdi, p. 4.

71. Paul Ricoeur, La mémoire, I'histoire, I'oubli, Paris, Seuil, 2000, p. 532-4.

72. L'élaboration du nationalisme soudanais fut l'entreprise d'un groupe relativement homogène (Musulmans arabophones du Nord) n'impliquant pas les populations du Sud. Pour des motifs stratégiques et religieux, I'administration coloniale britannique les avait largement isolées du Nord. C'est ainsi que le Sud-Soudan n'apparaît guère dans notre discussion. 